\title{
A Knowledge Management Framework for Remote Maintenance
}

\author{
http://dx.doi.org/10.3991/ijoe.v9i3.2786 \\ Jianwen Guo, Zhenzhong Sun, Rongyong Li, Haibin Chen, and Haizhou Xiao \\ DongGuan University of Technology, DongGuan, China
}

\begin{abstract}
Plant maintenance is a critical role in the success of manufacturing enterprises. The concept of remote maintenance (or e-maintenance) $n$ the industry refers to the integration of the information and communication technologies to service for plant maintenance remotely. Remote maintenance is characteristic of knowledge intensive and collaborative. To improve the efficiency of knowledge management and so as to improve the quality of remote maintenance work, a knowledge management framework was proposed. In the model, maintenance business ontology provides a common understanding for maintenance business to share information for knowledge management, and knowledge integration network describes the relationships among role knowledge, task knowledge and equipment knowledge, to achieve the integration of maintenance business and knowledge resources. At last, the paper illustrated the application of the proposed model. Results of this study can improve the level of knowledge management for remote maintenance.
\end{abstract}

Index Terms-remote maintenance, knowledge management, knowledge integration network, ontology

\section{INTRODUCTION}

Remote maintenance (or e-maintenance) is the totality of all maintenance, repair, overhaul and operation in the stage of use and maintain equipment remotely. It is a critical role in the success of manufacturing enterprises, and also is the core of the manufacturing services support technology [1]. Remote maintenance integrates maintenance theory in the information technology, communication, and enterprise management method to service for plant maintenance [2].

Remote maintenance is characteristic of knowledge intensive [3]. Each of Maintenance tasks requires employing of various knowledge and experience. Member of remote maintenance alliance has the willing to share knowledge, so as to cooperate with other members and finish the remote maintenance work. The key to successful remote maintenance is full understanding and effective sharing of knowledge throughout the remote maintenance cycle. Consequently, knowledge management approach capable of supporting the accumulation knowledge and experience in a distributed environment is one of the important guarantees to the successful execution of remote maintenance.

The research of knowledge management for remote maintenance has been emphasized in manufacturing industries, and many researches provide theories and methods for knowledge sharing of remote maintenance [49]. However, in addition to the effective sharing, knowledge also requires effective integration model to rapidly respond to the demand of maintenance work [10]. Few studies have focused on this issue.

According to the characteristics of business-driven and distributed cooperation, this paper proposes knowledge management framework for remote maintenance. In the framework, maintenance business ontology provides a common understanding for maintenance business to share information for knowledge management, and knowledge integration network describes the relationships among role knowledge, task knowledge and equipment knowledge, to achieve the integration of maintenance business and knowledge resources. The model can support the overall view of knowledge resources in remote maintenance, and to achieve the effective organization and application of maintenance knowledge.

\section{REMOTE MAINTENANCE PROCESS CHARACTERIZATIONS}

Remote maintenance concept model is shown as in Figure1. Remote maintenance is an approach to integrating resources from different enterprises to overcome the problem in plant maintenance and the tools/systems can be quickly and easily reconfigured by adding, adapting, adjusting and deleting individual tools/systems as needed. These tools/systems run on various platforms, which may be located in dispersed locations. Remote maintenance has the following characterizations:

Alliance Organization: organization structure of remote maintenance is maintenance alliance. Maintenance alliance is a virtual organization in which different enterprise share the processes, activities and resources of maintenance to provide a value-add maintenance services.

Business-centered: Participants in a remote maintenance process works together on a business with a commonly agreed time frame and have a common goal and well-defined responsibilities. Maintenance business is a process that consists of series of activities. An activity also can be further divided into lower level activities. This forms the hierarchical structure of processes.

Remote and On-line working: In addition to the necessary on-site operation, maintenance works are carried out by network remotely.

Distributed and cooperativeness: maintenance resources may be located in dispersed locations, and maintenance worker who take chare of the maintenance task may come from difficult enterprise. Individual activities performed together with other activities to achieve higher-level goals through communication and coordination. 


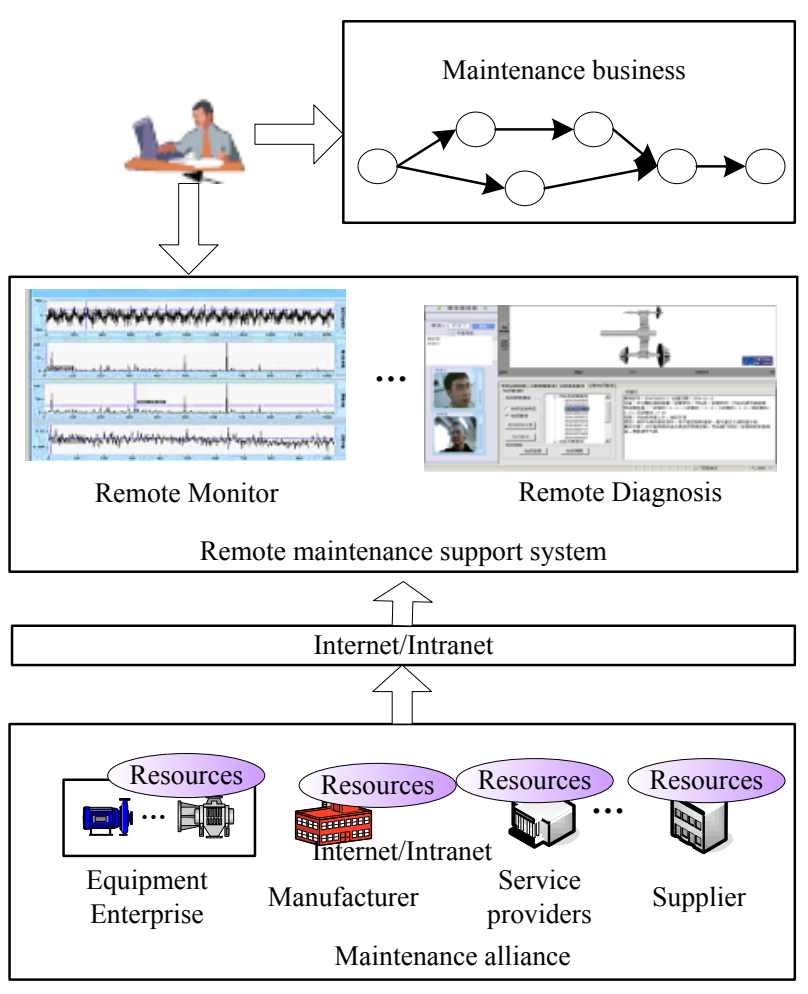

Figure 1. Remote maintenance concept model

Equipment-faced: remote maintenance processes are configured dynamically based on Mechanical Equipment characteristics and Mechanical Equipment maintenance life cycle.

\section{KNOWLEDGE MANAGEMENT FRAMEWORK FOR REMOTE MAINTENANCE}

According to the characterizations of remote maintenance, the framework of knowledge management is shown as in Figure 2. This framework is made up of Maintenance Business Ontology (MBO), Maintenance Knowledge Description Model (MKDM), and Knowledge Integration Network (KIN). Each part defined as follows:

Maintenance Business Ontology (MBO): The MBO is a sharable ontology built by the dominant enterprise to provide a common understanding for operational model of maintenance business. The MBO enables the federation members to share information on business for knowledge integration.

Maintenance Knowledge Description Model (MKDM): The MKDM is knowledge description model to provide registration specification for knowledge management. A collaborative enterprise registers a sharable knowledge object based on the MKDM and then knowledge management system integrate the knowledge item into knowledge network automatically.

Knowledge Integration Network (KIN): The KIN is made up of the logical relationships to achieve the integration of maintenance business and knowledge resources. The KIN is made up of Knowledge Object Graph (KOG), Enterprise Knowledge Node Graph (EKNG), Alliance
Knowledge Node Graph (AKNG. The KOG is made up of knowledge objects and their relations which defined by maintenance alliance. The EKNG is the mapping of the MBO and is made up of knowledge nodes and their relations within a collaborative enterprise. Each Alliance Knowledge Node (AKN) is the mapping of the concept in the MBO and links with one or more Enterprise Knowledge Nodes. Each Enterprise Knowledge Node (EKN) is the mapping of the concept in the MBO and links with one or more Knowledge Objects (KO). By using the knowledge integration mechanism, distributed EKNGs are integrated into the AKNG established by the dominant enterprise, hereby creating a global knowledge network with address connected physical knowledge. Thus, collaborating enterprises can share their own knowledge with other knowledge workers in collaborating enterprises to increase knowledge value.

\section{ESTABLISHMENT OF KNOWLEDGE MANAGEMENT FRAMEWORK}

\section{A. Establishment of $M B O$}

Ontology [11] is an explicit, shared and formal description of important concepts and their relationships. The purpose of ontology ies to define knowledge concepts within a specific domain using an interoperable format both humans and machines can understand, thereby realizing knowledge sharing and reuse. With the appropriate use of ontology, it is easy to realize semantic information exchange in knowledge management. Enterprise ontology is a collection of terms and definitions relevant to an enterprise to ensure that all parties involved have a shared understanding of the relevant aspects of an enterprise [12]. Enterprise ontology plays a crucial role in enterprise's knowledge management [13]. To establish a process-oriented knowledge supply model, enterprise ontology is also adopted to enable the e-maintenance federation to share commonsense concepts used in knowledge supply.

$\mathrm{MBO}$ can be expressed as:

$$
\mathrm{MBO}=(\mathrm{C}, \mathrm{R}) \text {. }
$$

Where $\mathrm{C}$ is ontology concept set, and $\mathrm{R}$ is ontology relation set.

Top level concepts and relations of MBO are shown as in Figure 3. Maintenance Activate Ontology (MAO) describes the activity concept and the relationship in the maintenance business. Maintenance Role Ontology (MRO) describes the role and relationship of the federation and maintenance members. Mechanical Equipment Ontology (MEO) describes the concept and relationship of equipment and its parts and reflects the hierarchy and structures of equipment parts.

\section{B. Establishment of MKDM}

MKDM can provide the overall view of the resources for knowledge management. MKDM is represented as follows:

MKDM = (Background, Content, Application $).$ 
PAPER

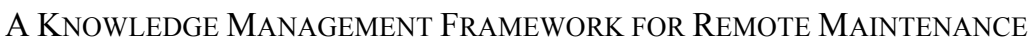
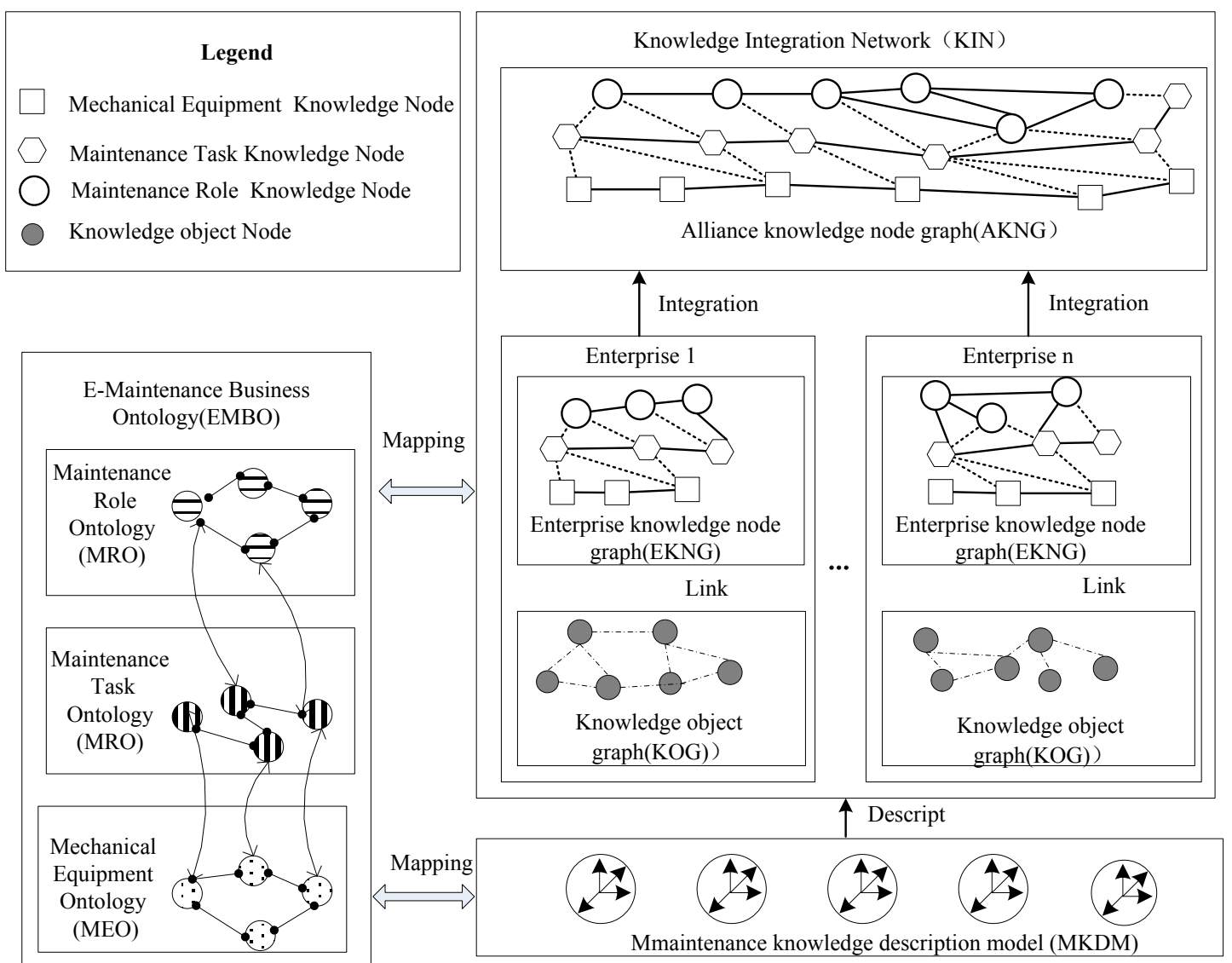

Figure 2. Knowledge Network Model for E-Maintenance

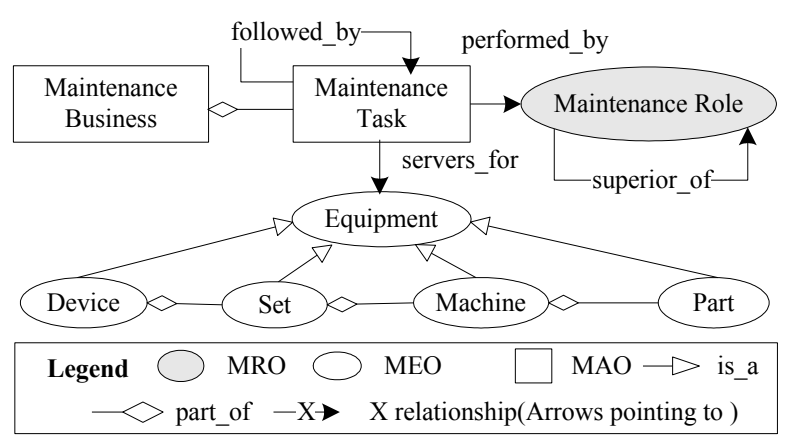

Figure 3. Top level concepts and relations of EMFO

Where Background is knowledge background, which has the basic information of the knowledge; Content is knowledge content, which describes the content of knowledge; Application knowledge application, which describes the applicable scope of the knowledge.

Background describes the background information of knowledge object. Background is represented as follows:

Background $=($ Owner, Author, CreationDate, ModifyDate).

Where, Owner is owner of knowledge object; Author is author of knowledge object; CreationDate is the date when knowledge object is created; ModifyDate is the date when knowledge object is modified.

Content describes function of knowledge content. Content is represented as follows:

Content $=($ Category, Level, Version, Keywords, Abstract , Evaluation, Location).
Category is classification of knowledge function, and is defined by maintenance alliance. Level reflects different structures and storage forms of knowledge. Level classifies knowledge into five knowledge levels of "Description", "Rule", "Procedure" and "Case". Version is the version of knowledge object. Abstract is abstract description of knowledge object. Keywords is a collection of words, which descript the function of knowledge object. Evaluation is evaluation value of knowledge quality. Location is the location of knowledge object.

Application is expressed as:

Application $=(M R S, M T S, M E S)$.

$M R S$ is the role set, which describes the suitable roles of knowledge. $M R S=\left\{R \mathrm{OC}_{1}, R \mathrm{OC}_{2}, \cdots, R \mathrm{O} C_{\mathrm{n}}\right\}, \quad R O C_{\mathrm{i}}$ $(1 \leq \mathrm{i} \leq \mathrm{n})$ is the concept of the MRO. MTS is the task set, which describes the suitable takes of knowledge. $M T S=\left\{A O C_{1}, A O C_{2}, \cdots, A O C_{\mathrm{m}}\right\}, A O C_{\mathrm{j}}(1 \leq \mathrm{j} \leq \mathrm{m})$ is the concept of MAO. MES is the equipment sets, which describes the suitable the suitable equipments of knowledge. $\quad M E S=\left\{E O C_{1}, E O C_{2}, \cdots, E O C_{\mathrm{p}}\right\}, \quad E O C_{\mathrm{k}}$ $(1 \leq \mathrm{k} \leq \mathrm{p})$ is the concept of MEO.

\section{Establishment of knowledge network model}

1. Knowledge node graph is directed graph which describes the knowledge nodes and their relationships. Knowledge node graph is defined as:

$$
G^{K N}=\left(V^{K N}, E^{K N}\right)
$$

$V^{K N}$ : Set of Knowledge Nodes (KNs),

$E^{K N}$ : Set of relations between Knowledge Nodes and $E^{K N} \in R$. 
$G^{K N}$ includes $G^{E K N}$ and $G^{A K N} 。 G^{E K N}$ is Enterprise Knowledge node graph which describes the Enterprise knowledge nodes(EKN) and their relationships; $G^{A K N}$ is alliance knowledge node graph which describes the Alliance knowledge nodes (EKN) and their relationships.

Definition 1: Knowledge Core (KC) is EMBO concept contained in knowledge node and each knowledge node has a $\mathrm{KC}$.

Definition 2: Knowledge Inventory (KI) is amount of knowledge contents within knowledge node. For AKN, KI is amount of EKNs within one AKN. For EKN, KI is amount of KONs within one EKN.

$A K N$ is defined as:

$$
A K N=\left(A K N I D, K C, K I, P_{A K N}\right)
$$

$A K N I D$ is the unique number of alliance knowledge node which maintenance alliance assign; $K C$ is Knowledge Core of $A K N ; K I$ is Knowledge Inventory of $A K N ; P_{A K N}$ is set of alliance knowledge node features, developed by maintenance alliance according to the application.

2. Knowledge object graph is Directed graph which describes the knowledge objects and their relationships. Knowledge object graph is defined as:

$$
G^{K O N}=\left(V^{K O N}, E^{K O N}\right),
$$

$V^{K O N}$ : Set of Knowledge Objects (KNs);

$E^{K O N}$ : Set of relations between Knowledge Objects. The types of $R^{K O N}$ is defined in Table2.

$E K N$ is defined as:

$$
E K N=\left(E K N I D, E I D, K C, K I, P_{E K N}\right)
$$

$E K N I D$ is the unique ID number of alliance knowledge node which enterprise alliance assign; $E I D$ is ID number of enterprise; $K C$ is Knowledge Core of $E K N ; K I$ is Knowledge Inventory of $E K N ; P_{E K N}$ is set of enterprise knowledge node features, developed by enterprise according to the application.

3. Knowledge link graph includes $G^{A E K N}$ and $G^{N O}$.

$G^{A E K N}$ is the link sets between alliance knowledge nodes and enterprise knowledge nodes. $G^{A E K N}$ is defined as:

$$
G^{A E K N}=\left\{a e l_{i j}, 1 \leqslant i \leqslant n, 1 \leqslant j \leqslant m\right\},
$$

$a e l_{i j}$ is the link between one alliance knowledge node and one enterprise knowledge node.

$$
a e l_{i j}=\left(a k n_{i}, e k n_{j}\right)
$$

$a k n_{i}$ is alliance knowledge node and $e k n_{\mathrm{j}}$ is enterprise knowledge node.

$G^{N O}$ is the link sets between enterprise knowledge nodes and knowledge object nodes. $G^{N O}$ is defined as:

$$
G^{N O}=\left\{\text { nol }_{i j}, 1 \leqslant i \leqslant n, 1 \leqslant j \leqslant m\right\},
$$

$n o l_{i j}$ is the link between one enterprise knowledge node and one knowledge object node.

$$
n o l_{i j}=\left(e k n_{i}, k o n_{j}\right) \text {, }
$$

$e k n_{i}$ is enterprise knowledge node and $k o n_{j}$ is knowledge object node.

$$
K O N \text { is defined as: }
$$

$$
K O N=(K O N I D, E I D, K O L)
$$

$K O N I D$ is the unique ID number of knowledge object node which enterprise assign; EID is ID number of enterprise; $K O L$ is location of knowledge object which link with knowledge object.
Based above define, the data structure of the model is shown as in Figure 4.

\section{APPLICATION}

Based the knowledge management framework for remote maintenance, a knowledge management system had been developed (Figure 5).

Functions of system are as follows:

1. The Ontology Management supports the construction and maintenance of MBO. The system uses Protégé to develop the MBO and Jena [14] to enable creation, modifying, maintenance of ontology. Figure 6 is Protégé development interface of MBO.

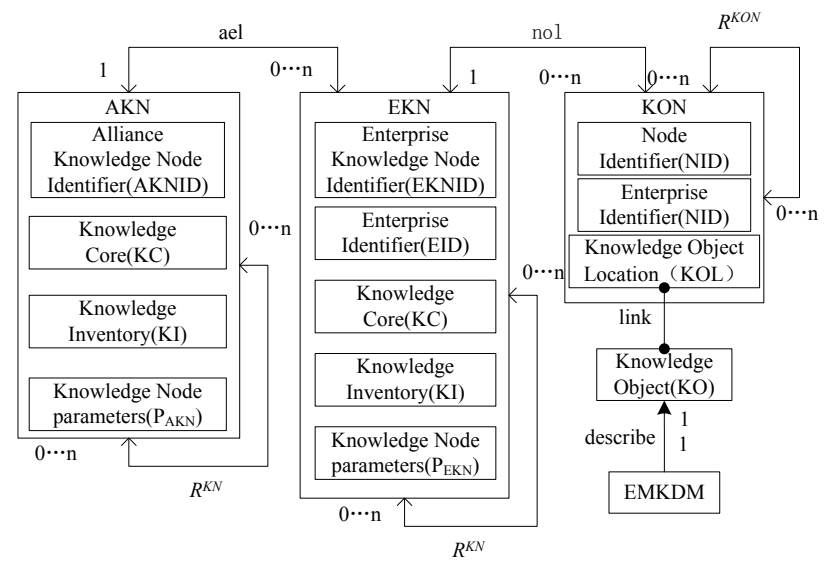

Figure 4. Data structure of the model

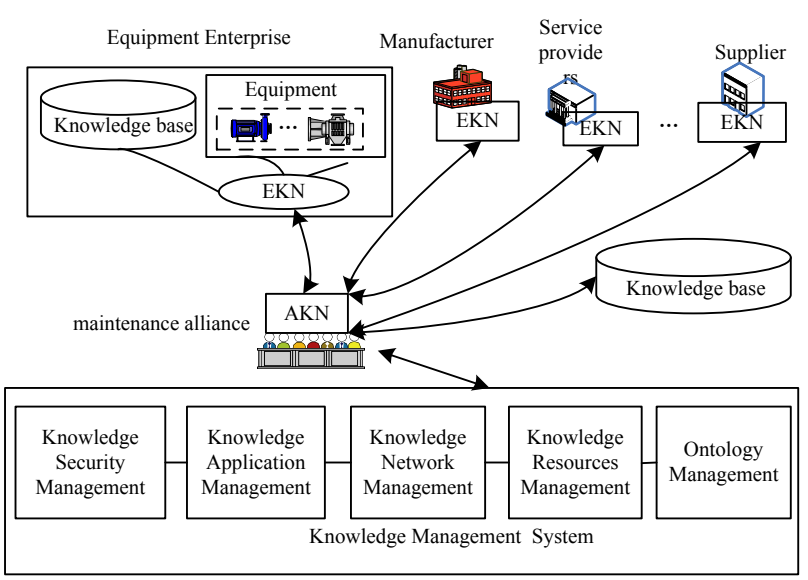

Figure 5. Knowledge management system

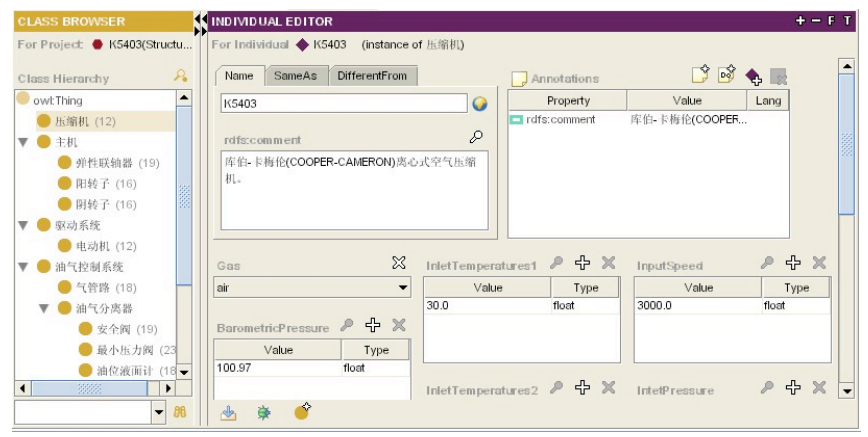

Figure 6. Protégé development interface of MBO 
PAPER

A KNOWLedge Management Framework for Remote MaintenanCe

2. The Knowledge Resources Management supports registration, query and maintenance of knowledge object. Figure 7 is Knowledge object register interface.

3. The Knowledge Network Management supports creation, deletion and integration of knowledge nodes. Knowledge node search interface is shown as in Figure 8

4. The Knowledge Application Management takes business process as the core and integrates knowledge resources in order to adapt to the maintenance business operation. Its development is based process-oriented knowledge supply model [3] which the author had been developed.

5. The Knowledge Security Management takes business process as the core to protect the knowledge. Its develop- ment is based business-process-context-based knowledge access control model [15] which the author had been developed.

\section{CONCLUSION}

Knowledge is one of core e-maintenance resources and critical support element of maintenance process. The knowledge management framework is proposed to achieve the integration of maintenance business and knowledge resources. From the application, it is known that the model can support the navigation knowledge, supply activities, and improve the efficiency of knowledge management.

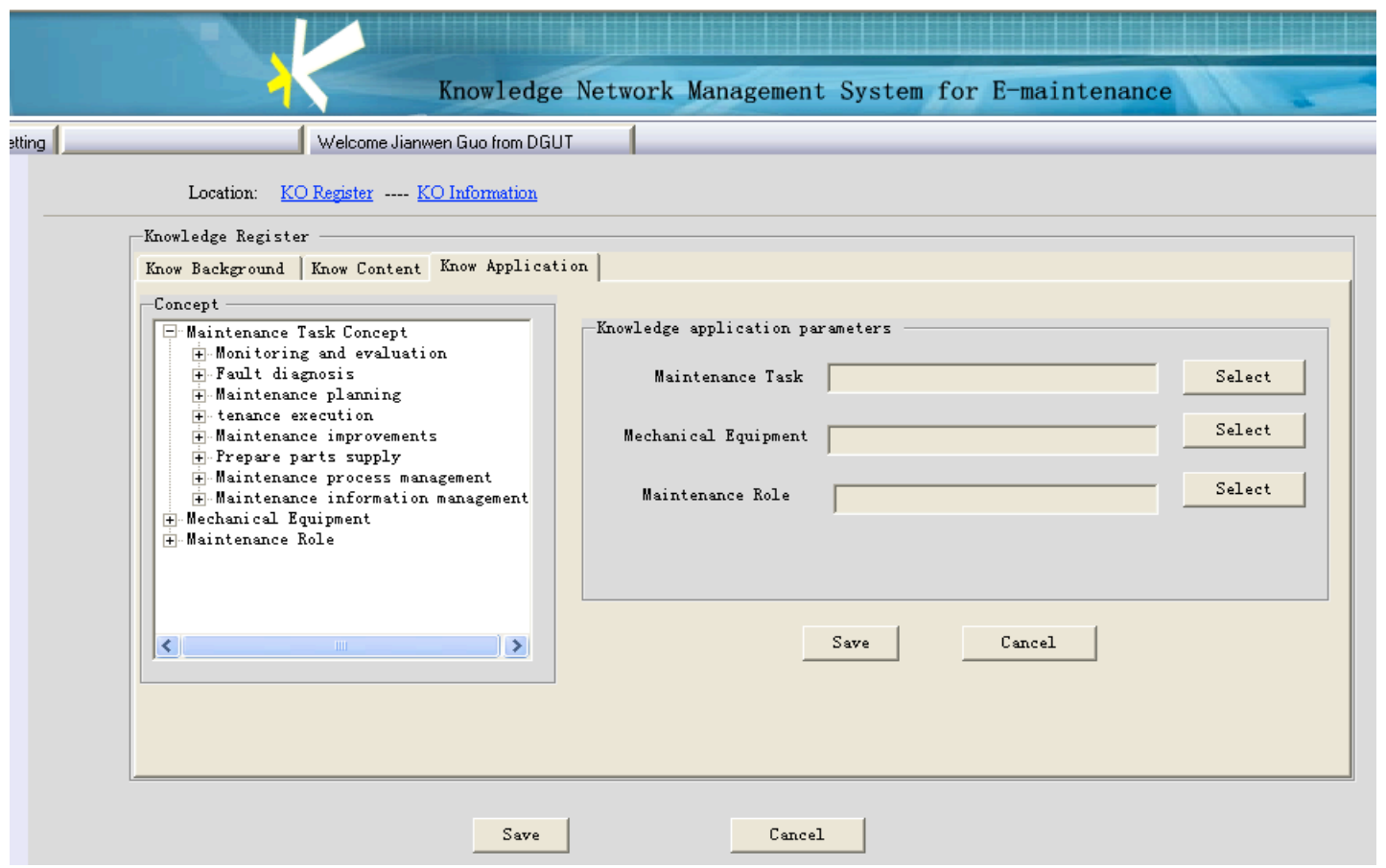

Figure 7. Knowledge object register interface

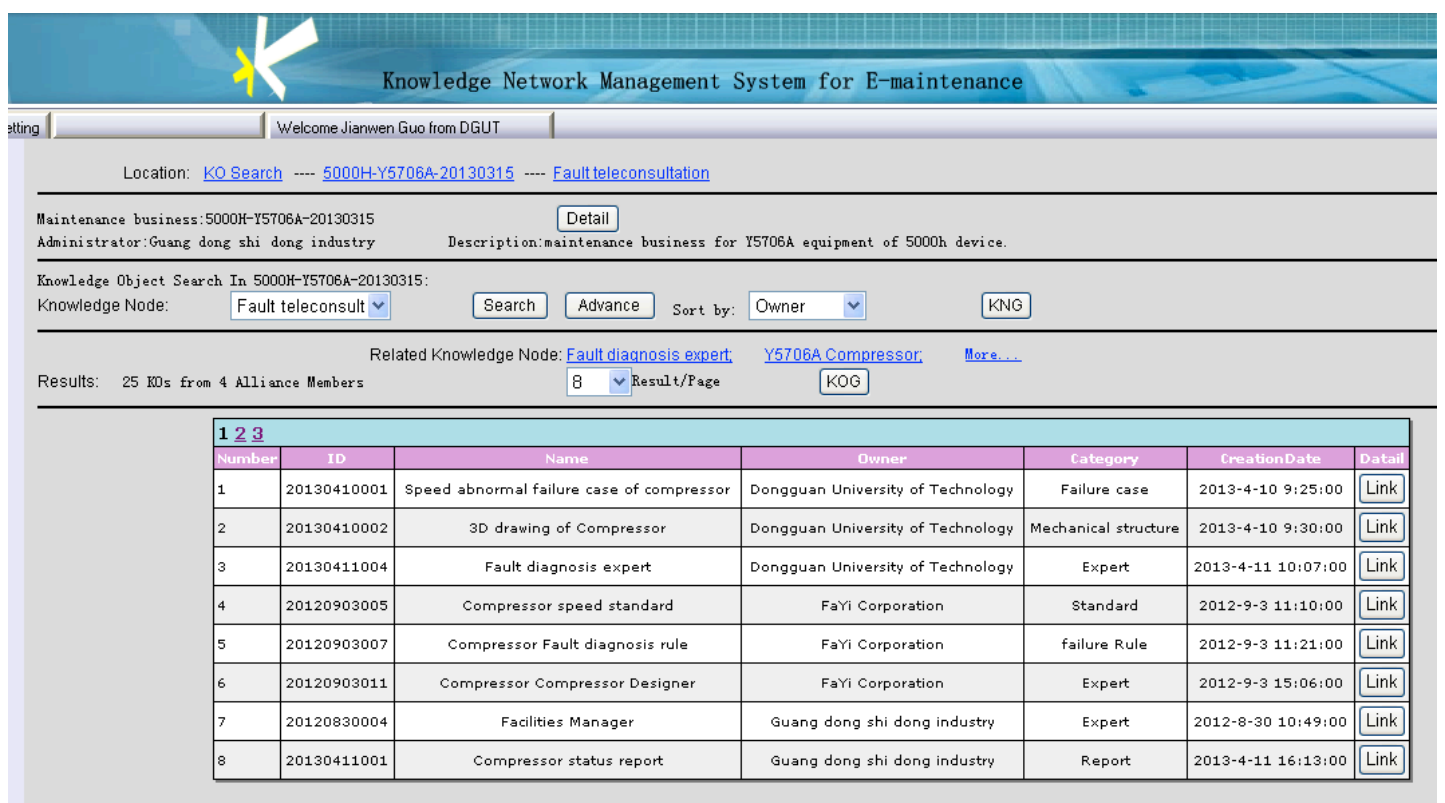

Figure 8. Knowledge node search interface 


\section{REFERENCES}

[1] Levrat E, Iung B Marquez A C. E-maintenance: review and conceptual framework. Production Planning \& Control, 2009, 19(4): 408-42 http://dx.doi.org/10.1080/09537280802062571

[2] Muller A, Marquez A C, Iung B. On the concept of e-maintenance: review and current research. Reliability Engineering \& System Safety, 2008: 93(8): 1165-1187 http://dx.doi.org/10.1016/j.ress.2007.08.006

[3] Jianwen Guo, Dejie Yu. Development of Process-oriented Knowledge Supply Model for E-maintenance. Advances in Information Sciences and Service Sciences, 2012, 4(10): 293-302. http://dx.doi.org/10.4156/ aiss.vol4.issue 10.35

[4] R. Ivana, C.M. Brigitte, Z. Noueeddine, "Process of s-maintenance: decision support system for maintenance intervention", In Proceedings of the 10th IEEE Conference on Emerging Technologies and Factory Automation, pp. 679-686, 2005.

[5] X. Ren, M. Ong, G. Allan, V. Kadirkamanathan, H.A. Thompson, P.J. Fleming, "Service-oriented architecture on the grid for integrated fault diagnostics", Concurrency and Computation: Practice and Experience, vol. 19, no. 2, pp. 223-234, 2007. http://dx.doi.org/10.1002/cpe.1047

[6] M.H. Hung, F.T. Cheng, S.C. Yeh, "Development of a web-servicesbased e-diagnostics framework for semiconductor manufacturing industry", IEEE Transactions on Semiconductor Manufacturing, vol. 18, no. 1, pp.122-135, 2005. http://dx.doi.org/10.1109/TSM.2004.836664

[7] M.H. Hung, K.Y. Chen K Y, R.W. Ho, F.T. Cheng, "Development of an e-diagnostics/maintenance framework for semiconductor factories with security considerations", Intelligent Maintenance Systems, vol.17, no. 3-4, pp. 165-178, 2003.

[8] M.H. Hung, T.L. Wang, F.Y. Hsu, F.T. Cheng, "Development of an interface c framework for semiconductor e-diagnostics systems", Robotics and Computer-Integrated Manufacturing, vol.24, no. 3, pp. 370-383, 2008. http://dx.doi.org/10.1016/j.rcim.2007.02.020

[9] L. Zhen, Z. Jiang, "Knowledge grid based knowledge supply model", IEICE Transactions on Information and Systems, vol. E91-D, no. 4, pp.1082-1090, 2008.

[10] Jianwen Guo, Jianjun Zou, Haibin Chen. Development of Knowledge Integration Model for E-Maintenance. Research Journal of Applied Sciences, Engineering and Technology, 2013, 5(5): 1841-1847.

[11] C. Brewster C, K. Hara, "Knowledge representation with ontologies: the present and future", IEEE Computer Society, vol.19, no. 1, pp. 72-81, 2004

[12] D. Kang, J. Lee, S. Choi, K. Kim, "An ontology-based enterprise architecture", Expert Systems with Applications, vol. 37, no. 2, pp. 1456-1464, 2010. http://dx.doi.org/10.1016/j.eswa.2009.06.073

[13] J.H. Park, K.H. Kim J.H. J. Bae, "Analysis of shipbuilding fabrication process with enterprise ontology", Computers in Human Behavior, vol. 27, no. 5,pp. 1519-1526, 2011. http://dx.doi.org/10.1016/j.chb.2010. 10.021

[14] http://jena.apache.org/

[15] Jianwen Guo, Dejie Yu. Business-Process-Context-based Knowledge Access Control Model for E-Maintenance. Advances in Information Sciences and Service Sciences, 2012, 4(17):316-323, 2012

\section{AUTHORS}

Jianwen Guo received his Ph.D. degree in Mechanical Engineering from Hunan University, China in 2010. He is currently a lecturer in the School of Mechanical Engineering, DongGuan University of Technology, China. His research interests include computer integrated manufacturing system, mechanical maintenance and knowledge management (e-mail: guojw@dgut.edu.cn).

Zhenzhong Sun received his Ph.D. degree from Harbin Institute of Technology, China. He is currently a professor in the School of Mechanical Engineering, DongGuan University of Technology, China. His research interests include computer integrated manufacturing system, mechanical maintenance (email: sunzz@dgut.edu.cn).

Rongyong Li received his bachelor degree in Mechanical Engineering from DongGuan University of Technology, China in 2007. He is currently an engineer in the School of Mechanical Engineering, DongGuan University of Technology, China. His research interests in mechanical maintenance (e-mail: liry@dgut.edu.cn).

Haibin Chen received his bachelor degree in Mechanical Engineering from DongGuan University of Technology, China in 2007. He is currently an engineer in the School of Mechanical Engineering, DongGuan University of Technology, China. His research interests in mechanical maintenance (e-mail: chenhb@dgut.edu.cn).

HaiZhou Xiao received his bachelor degree in Mechanical Engineering from DongGuan University of Technology, China in 2013. He is currently an engineer in the School of Mechanical Engineering, DongGuan University of Technology, China. His research interests in mechanical maintenance (e-mail: xiaohz@dgut.edu.cn).

This article is an extended and modified version of a paper presented at the International Conference on Mechanical Engineering, Automation and Material Science (MEAMS2012), held 22-23 December 2012, Wuhan, China. It was supported by the China Spallation Neutron Source Electromechanical Technology R \& D Joint Laboratory (ZD120512) and the Research Starting Foundation from DongGuan University of Technology (ZJ120424). Received 17 May 2013. Published as resubmitted by the authors 12 June 2013. 